\title{
Outbreak of COVID-19 on an industrial ship
}

\section{Ewout Fanoy ${ }^{1}$, Anke Elisabeth Ummels ${ }^{1}$, Valerie Schokkenbroek ${ }^{1}$, Bas van Dijk ${ }^{2}$, Saskia Wiegmans ${ }^{2}$, Thijs Veenstra ${ }^{3}$, Annemiek A. van der Eijk ${ }^{4}$, Reina S. Sikkema ${ }^{4}$, Annemieke de Raad ${ }^{1}$}

${ }^{1}$ Municipal Public Health Service Rotterdam-Rijnmond, Rotterdam, Netherlands

${ }^{2}$ Harbour Coordination Centre, Rotterdam, Netherlands

${ }^{3}$ National Institute for Public Health and the Environment (RIVM), Bilthoven, Netherlands

${ }^{4}$ Department of Viroscience, Erasmus Medical Centre, Rotterdam, Netherlands

\begin{abstract}
Background: People on ships are at high risk for outbreaks of infectious diseases including coronavirus disease 2019 (COVID-19). A rapid and well-coordinated response is important to curb transmission of severe acute respiratory syndrome coronavirus 2 (SARS-CoV-2). We studied an outbreak on an industrial ship to improve outbreak control for ships and coordination between participating harbour partners.

Materials and methods: Public Health Service (PHS) Rotterdam-Rijnmond performed an epidemiological investigation during the outbreak of COVID-19 among 77 seafarers on a ship in their port. The captain was interviewed about ship details and his experiences during the outbreak. The seafarers were asked to fill in questionnaires about symptoms suspicious of COVID-19 and date of symptom onset. Information about stakeholders involved in outbreak control was registered.

Results: The captain first contacted PHS about probable cases on March $31^{\text {st }} 2020$ via a physician ashore. One crewmember was hospitalised on April $8^{\text {th }}$ and another died unexpectedly aboard on April $10^{\text {th }}$. Questionnaires distributed mid-April to the 75 remaining seafarers showed that 38 of 60 responders (63\%) had had suspicious symptoms between February $15^{\text {th }}$ and April $13^{\text {th }}$. None of them were tested but a total of 8 other crewmembers tested positive for COVID-19 after leaving the ship, including the hospitalised crewmember and the one who died aboard. On May $5^{\text {th }}$, the last case left isolation and the quarantine ended. Many different stakeholders were involved in the outbreak response and responsibilities were not always fully clear beforehand, causing coordination issues.

Conclusions: Testing crew with COVID-19 symptoms underpins control measures and clarifies communication between stakeholders. Building a-network beforehand to develop outbreak guidelines tailored to ships and local circumstances is essential to control future outbreaks on ships.
\end{abstract}

(Int Marit Health 2021; 72, 2: 87-92)

Key words: COVID-19, SARS-CoV-2, coronavirus, outbreak, ship, harbour, public health service

\section{INTRODUCTION}

In December 2019, an outbreak of a novel coronavirus - severe acute respiratory syndrome coronavirus 2 (SARS-CoV-2), first detected in Wuhan, China, rapidly spread throughout the world [1]. Since the beginning of the pandemic, several outbreaks on ships have been described worldwide [1-6]. Once SARS-CoV-2 is introduced, ships are at high risk for an outbreak due to crew working closely together in confined spaces $[2,7,8]$. Here we describe an outbreak among the crew of an industrial ship, from a public health point of view. We highlight the complexity of coordination of control measures and share lessons learned.

\section{MATERIALS AND METHODS}

A possible outbreak of coronavirus disease 2019 (COVID-19) in the port of Schiedam, the Netherlands, was reported on March $31^{\text {st }}$ to the Public Health Service 
Table 1. Parties responding during an outbreak of coronavirus disease 2019 (COVID-19) on a ship in a Dutch port, with description of their roles

\begin{tabular}{|c|c|}
\hline Captain & Responsible for crew on board the ship. \\
\hline Ship`s port agent & $\begin{array}{l}\text { Facilitate logistics and communication between the captain and PHS in } \\
\text { different harbours. }\end{array}$ \\
\hline Shipping company & $\begin{array}{l}\text { Owns the ship, communicates with captain arranging logistics and financial } \\
\text { issues. }\end{array}$ \\
\hline Public Health Services (PHS) & $\begin{array}{l}\text { Responsible for outbreak control in the region. The PHS gives advice about } \\
\text { response measures and informs the safety region, press and National Institute } \\
\text { for RIVM. }\end{array}$ \\
\hline Regional Harbour Coordination Centre (HCC) & $\begin{array}{l}\text { Informs the harbour master, press, and facilitates contact between the PHS, } \\
\text { the captain and the shipping agent. }\end{array}$ \\
\hline $\begin{array}{l}\text { National Institute for Public Health and } \\
\text { the Environment (RIVM) }\end{array}$ & $\begin{array}{l}\text { National focal point for European Union member states considering cross } \\
\text { border travel of COVID-19 cases. }\end{array}$ \\
\hline Regional Safety Force (RSF) & $\begin{array}{l}\text { Regional government body informing and coordinating actions between the } \\
\text { police, the ambulances, the fire department and PHS. }\end{array}$ \\
\hline
\end{tabular}

(PHS). The outbreak location was a 600-foot (183 m) ship under Bahamian flag, designed to lay pipes at the seabed.

The ship had been in Pointe Noire, Congo-Brazzaville, for 9 weeks before departing with 134 crew on board on December $26^{\text {th }}, 2019$. Eight crewmembers debarked in African ports before the ship arrived in the port of Schiedam, a city next to Rotterdam, on January $23^{\text {rd }}, 2020$, where another 49 members debarked. Two service engineers boarded on several occasions up to March $4^{\text {th }}$ for maintenance work. An Italian food company, with staff directly transporting the food supplies from Italy to the Netherlands, delivered to the ship on March $21^{\text {st }}$.

The remaining 77-man mainly Filipino and Malaysian crew included a Filipino physician and a Dutch captain, who boarded March $31^{\text {st }}$.

When the new captain boarded and noticed that several crewmembers were ill, he isolated all crew with respiratory symptoms. He notified a port physician, who alerted the PHS about a possible COVID-19 outbreak on the ship. The PHS informed the Harbour Coordination Centre in Rotterdam (HCC) and gave basic advice on outbreak control to the captain such as isolation, social distancing and detailed hygiene practices, according to Dutch national guidelines.

When on April $8^{\text {th }}$ one crewmember had to be hospitalised, the captain contacted the HCC about that and an increasing number of cases. The HCC informed the PHS and then PHS started an outbreak investigation. At this time the outbreak had also received a lot of local media attention.

The PHS kept a record of communication with different stakeholders in the harbour (i.e. HCC, shipping agent, captain, ship company, sea pilots, hospital staff, laboratory staff, medical doctor working on the ship, medical doctor working in the harbour, national focal point (National Institute for Public Health and the Environment [RIVM]) and the Regional Safety Force (RSF), which is responsible for responding to different types of crises (Table 1).

The PHS sent two different questionnaires to the captain on April $13^{\text {th }}, 2020$. The first questionnaire was addressed only to the captain and concerned general information about the ship, the ship's travel log, and outbreak control measures that had been implemented. The captain printed and distributed the second questionnaire to each crewmember, requesting case related information (date of onset of symptoms, complaints, contacts with other crew, activities and preventive measures taken).

Cases were classified as probable when they had at least one of the following symptoms: fever, coughing, loss of taste or smell, headache, vomiting, nausea, sore throat, muscle or joint pain, or tiredness.

\section{CONFIRMED CASES}

Due to scarce testing materials at the time, no crewmembers were tested on board. On April $8^{\text {th }}, 1$ case was hospitalised with severe shortness of breath, and on April $9^{\text {th }}$ he was confirmed SARS-CoV-2 positive by a polymerase chain reaction (PCR) test. One crewmember-died unexpectedly on April $10^{\text {th }}$. SARS-CoV-2 was confirmed post-mortem by PCR ashore. After April $6^{\text {th }}$ another 6 crewmembers who had left the ship without symptoms were confirmed PCR-positive after repatriation.

\section{SELF-REPORTED CASES}

Sixty out of 75 non-tested crewmembers still aboard filled in a questionnaire, and 38 (63\%) reported COVID-19 related symptoms (Fig. 1). Symptoms of the first probable case started on February $15^{\text {th }}$, 


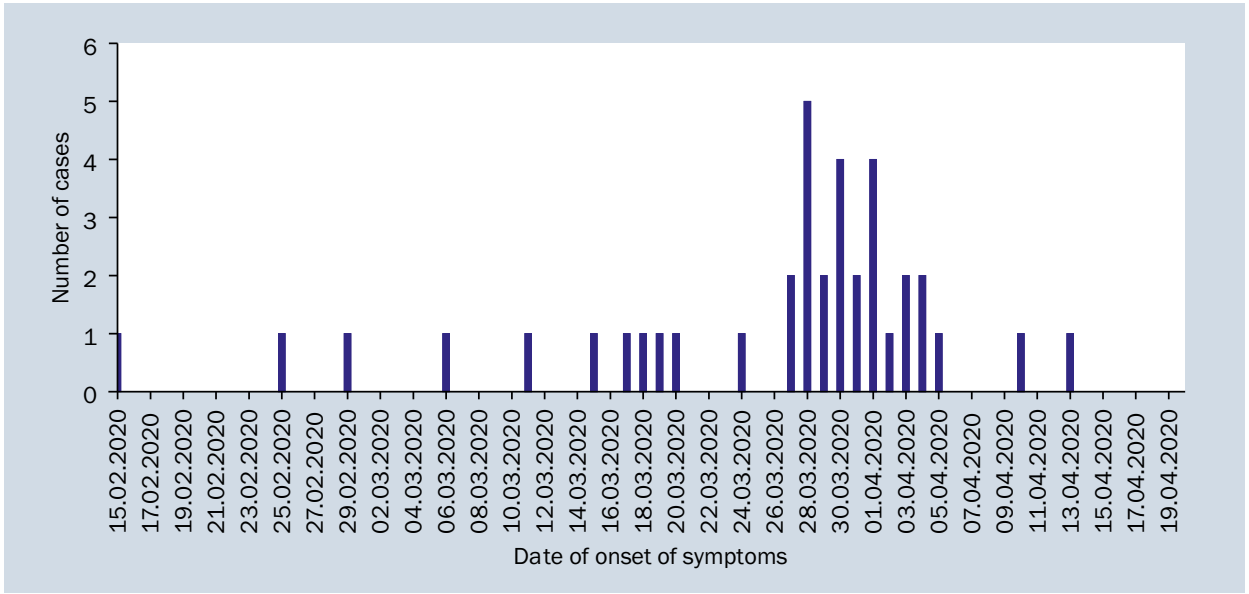

Figure 1. Coronavirus disease 2019 (COVID-19) outbreak on a Bahamian-registered ship in a Dutch port: Timeline for onset of symptoms reported by 38 of 60 seafarers who responded to a questionnaire distributed mid-April 2020 to 75 non-tested crewmembers still aboard

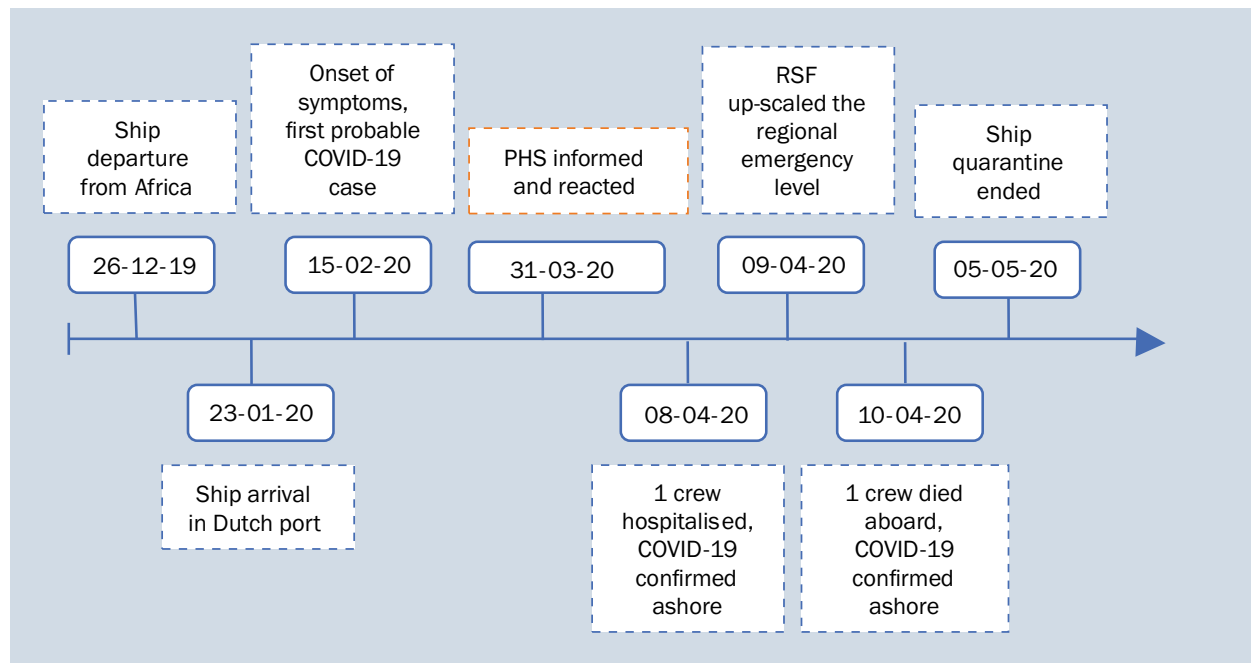

Figure 2. Timeline for key events regarding a coronavirus disease 2019 (COVID-19) outbreak on a Bahamian-registered ship that arrived in a Dutch port with 77 seafarers. A questionnaire about COVID-19 symptoms and date of onset was distributed mid-April 2020 to 75 non-tested crewmembers still aboard. Of 60 responders, 38 reported one or more COVID-19-related symptoms; PHS - Public Health Services; RSF - Regional Safety Force

2020. The number of cases rose until March $27^{\text {th }}$, peaking on March $28^{\text {th }}$. The last case reported first symptoms on April $13^{\text {th }}$. On May $5^{\text {th }}$, the final case left isolation and ship quarantine ended. Figure 2 shows some key events of the outbreak along a timeline.

\section{PATIENT DETAILS}

Based on the questionnaire data, the 38 ill crewmembers were between 25 and 60 years of age (median 32) and all were male. The median duration of symptoms was 7 days. Most frequent symptoms were mild cold symptoms $(n=24)$, muscle pain $(n=22)$, headache $(n=21)$, loss of smell or taste $(n=14)$ or cough $(n=12)$. Fever was mentioned 3 times (Fig. 1).

\section{CONTROL MEASURES ON THE SHIP}

On March $31^{\text {st }}$, a Dutch captain arrived on board after 14 days of quarantine at home. Before his arrival, some crewmembers had had mild respiratory complaints, but at first these complaints were assigned to the temperature change from Africa to the Netherlands.

On March $31^{\text {th }}$, however, the new captain announced some general restrictions to the crew. They were not allowed to disembark for even short trips ashore. The ship's doctor was involved in treatment and isolation of potential COVID-19 cases. Seventeen symptomatic crewmembers were promptly isolated. Later that day, a port physician, notified by the captain, discussed the sick seafarers with the PHS. The PHS agreed with the implemented control 
measures and gave some additional advice based on Dutch COVID-19 guidelines. These measures were social distancing (based on the 5 feet distance principle) and cabin-isolation for symptomatic individuals until at least 24 hours after clinical recovery. The captain actively communicated the measures to the crew. In addition, the company that supplied medical services to the ship went beyond PHS recommendations and advised that symptomatic crewmembers should be kept in isolation for 14 days. Following PHS advice, every crew member was assigned a separate cabin. The HCC ordered the captain to suspend ship operations.

The ship's doctor had enough personal protective equipment (PPE) to protect himself during patient visits. Isolated crew was allowed to walk 1 hour per day on deck while using PPE. The doctor checked their temperature daily and supplied them with medication when needed. The non-isolated crew on board the ship continued to do necessary maintenance work, and therefore could not be quarantined at all times in their cabins. PPE (gloves, masks) were then used. To minimise the risk of infecting co-workers, small fixed crew groups worked in shifts. The PHS advised that the ship and crew should remain in port until quarantine of the last crewmember had ended to avoid them becoming (seriously) ill at sea.

Starting March $31^{\text {st }}$, kitchen staff wore masks and latex gloves. The number of crew allowed to eat in the galley at the same time was reduced in order to facilitate social distancing. Common areas such as the gymnasium were temporarily closed. Extra cleaning staff was hired to clean the common areas and cabins. The captain had daily contact with the medical service of the shipping company about the on-board health situation and measures taken. After the outbreak, the company required all new crew to quarantine themselves for 14 days before embarkment, followed by a pre-boarding PCR-test to minimise the risk of further SARS-CoV-2 transmission.

\section{STAKEHOLDERS INVOLVED}

During the outbreak response, many different parties were involved (Table 1). Here we present a brief summary to illustrate the complexity of the network of stakeholders involved in the management of an outbreak on a single ship.

The captain was responsible for the crew on board. The ship was owned by a company, which communicated with the captain and dealt with logistic and financial issues. The company also discussed quarantine measures with the captain. They were sometimes more stringent than those advised by the PHS. Shipping companies usually use port agencies to facilitate logistics and communication with the captain and PHS in the various harbours. The ship was docked at a terminal owned by the ship company. Staff members working in the terminal were involved in logistics around the moored ship. The crew included a medical doctor. A general physician (port doctor) visited the ship at the request of the captain to assist in diagnosis and care when COVID-19 was suspected.

The PHS was responsible for outbreak control in the region, including in the harbour. PHS-staff advised the regional $\mathrm{HCC}$ and the captain about response measures. The PHS informed the mayor of the city, who is responsible for the safety of the citizens and is head of the RSF, which includes the police, the fire department, ambulances and the PHS.

The HCC informed the harbour master about the outbreak. The HCC was in contact with sea pilots when the ship had to relocate to another part of the harbour.

When a crewmember had to be hospitalised, an ambulance, the police and the hospital, including the laboratory, were involved in patient transport and care. Due to the hospitalisation of the crewmember, the RSF increased the alarm phase temporarily on April $8^{\text {th }}$, to coordinate the response of public services such as ambulances, police, the fire department and PHS in the direct surrounding of the ship. This generated media attention. The PHS and HCC worked together to ensure that the press was properly informed, and the alarm phase was quickly decreased.

COVID-19 is considered a disease of (inter-)national concern and therefore guidance is directed from the national government. The PHS updated the RIVM about the outbreak. The PHS requested the laboratory of the hospital to perform sequence analysis of the PCR-positive specimens. RIVM, the national focal point for the World Health Organization and the European Centre for Disease Prevention and Control, was informed by another European Union (EU) member state about a crewmember who tested positive after returning home.

\section{DISCUSSION COORDINATION OF OUTBREAK MEASURES}

The main purposes to take measures during an outbreak are to limit the transmission on the ship and to protect the population on land. It is very hard to prevent transmission between crew members while aboard a ship, but we drew some lessons from this outbreak which could improve speed of diagnostic and medical process, and communication with the different stakeholders in the future.

To start, early detection and disembarkation of positive cases, or complete crew change, have been suggested to stop further transmission [7]. It is advisable to have a detailed plan ready for both the PCR-negative and PCR-positive tested crew and to inform the total crew about this plan. The PHS had to arrange practical issues in collaboration with the other stakeholders, without a clear guideline that is specific to the regional circumstances and typical ship and crew issues. For example: evacuation of high-risk contacts has challenging issues such as visa-issues, arrangement 
of a suitable quarantine location, and rules for crossing borders. It is also unclear who is responsible for costs [8]. It is helpful to describe beforehand who is responsible when an outbreak on a ship occurs for which actions, including measures taken on board, measures taken on shore, and communication.

We learned that an outbreak on a ship is challenging, and can draw media attention, especially when the regional alarm phase is increased, followed by visible police and ambulance response near the ship. We therefore advise public health services to clarify for themselves the roles and responsibilities of all main parties involved, so a more detailed response plan is ready when necessary. As illustrated, there are many organizations involved during an outbreak on a ship. We learned that it is necessary to align the PHS outbreak management policy with the shipping company and the ship's port agent, as the captain receives instructions from both. The policy and status of the outbreak must be explained and regularly updated to all parties involved, including harbour staff, such as police and sea pilots, since we experienced unrest among them. Clear communication is eminent. To accommodate outbreak management in the future, we strongly advise building an active network between all relevant parties in the harbour, for example by organizing simulated outbreaks.

In order to protect staff against infection and to be time efficient, the PHS did not visit and inspect the ship. All communication with stakeholders was done via telephone and email. Other subsequent outbreaks have taught us that a site visit generates a more detailed understanding of the situation, enables the inspection of hygienic standards and ventilation options, and improves trust in the advice given to the crew.

In the harbour area of Rotterdam, a location is reserved for quarantined ships. Appropriate isolation and hygiene measures on board are necessary to reduce the risk of transmission on the ship. Unfortunately, it is not always feasible to isolate or quarantine people on board. Ideally the ship company organises a quarantine location, such as a hotel, arranges logistics of crew, and pays for the costs. On a public health level, it seems wise to prepare for quarantines of larger numbers of crew or passengers of cruise ships. Therefore, it is relevant to have a location on shore dedicated for isolation or quarantine purposes.

\section{DIAGNOSTIC TESTING}

Some crew members, both symptomatic and asymptomatic, indicated that they wanted to be tested for COVID-19. But following national guidance at March 31 ${ }^{\text {st }}$, laboratory confirmation of mildly sick cases was not recommended by the national guidelines at the time. The crew was not considered to be a vulnerable population at risk for severe infections, there was a national shortage of testing materials, and the PHS did not question COVID-19 as a most likely source of the outbreak: a positive diagnosis would not change the preventive measures advised. However, laboratory testing was initiated 8 times by other, non-PHS, health professionals. Their reasons to test were not public health related, but part of prevention policy in a hospital setting, to confirm individual diagnosis, or to allow travel. Considering the multiple partners involved in ship logistics, early confirmation of COVID-19 could have been helpful for a clearer communication. Especially for repatriating crew, a negative PCR-result can be relevant to allow flying or crossing borders. Additional testing can also be helpful to monitor the transmission of the virus on board.

\section{SIGNALLING OUTBREAKS}

The PHS did not receive a Maritime Declaration of Health (a requirement for captains in order to inform the HCC about sick crew), before entering the port, as the ship had already entered the harbour before the first case was noticed. It should be made clear to captains how, when and where to notify suspected cases and how to test them, once a ship has moored.

The PHS did not immediately inform the RIVM about the outbreak, as it did not expect crew to disembark and travel back home to other countries. Consequently, the notification of a case by another EU-member state to the RIVM was a surprise. In light of this experience, it is advisable to inform the national focal point when COVID-19 cases are detected on ships with an international crew.

The PHS did not notify the outbreak in the 'EU Shipsan Information System' (SIS; http://www.shipsan.eu/), as the ship was not travelling to other harbours or countries during the outbreak. Nevertheless, it is worth discussing when to declare an outbreak on a ship to be over and worth registering.

\section{CONCLUSIONS}

Testing of crew with respiratory symptoms during an outbreak in general and during a COVID-19 pandemic specifically, is advisable as it promotes acceptance of the control measures and clarifies communication between different stakeholders. During outbreaks, it is relevant to include both the captain and the shipping company in the communication. Considering the many parties involved, it is worthwhile to invest in network building beforehand, to develop outbreak guidelines tailored to ship-related issues and the regional circumstances, and to do exercises to test practical issues.

\section{ETHICAL CLEARANCE}

Outbreak investigations of notifiable diseases such as COVID-19 are the legal tasks of Public Health Services as described under the Public Health Act, and do not require separate medical ethical clearance. 


\section{DATA SHARING}

All relevant data for this short report are within the paper. The authors support the policy of making relevant anonymised patient level data available on reasonable request. Requests should be directed to: eb.fanoy@rotterdam.nl.

\section{ACKNOWLEDGEMENTS}

We are grateful for textual edits from Jane Whelan. Robert-Jan Hoogerwerf assisted with data-analysis. We thank the captain of the ship for sharing information.

\section{REFERENCES}

1. Zhu Na, Zhang D, Wang W, et al. A novel coronavirus from patients with pneumonia in China, 2019. N Engl J Med. 2020; 382(8): 727-733, doi: 10.1056/NEJMoa2001017, indexed in Pubmed: 31978945.

2. Moriarty LF, Plucinski MM, Marston BJ, et al. Public Health Responses to COVID-19 Outbreaks on Cruise Ships - Worldwide, February-March 2020. MMWR Morb Mortal Wkly Rep. 2020; 69(12): 347-352, doi: 10.15585/mmwr.mm6912e3, indexed in Pubmed: 32214086.
3. Nakazawa E, Ino H, Akabayashi A. Chronology of COVID-19 Cases on the Diamond Princess Cruise Ship and Ethical Considerations: A Report From Japan. Disaster Med Public Health Prep. 2020; 14(4): 506-513, doi: 10.1017/dmp.2020.50, indexed in Pubmed: 32207674.

4. Koh D. Occupational risks for COVID-19 infection. Occup Med (Lond). 2020; 70(1): 3-5, doi: 10.1093/occmed/kqaa036, indexed in Pubmed: 32107548.

5. Dahl E. Coronavirus (COVID-19) outbreak on the cruise ship Diamond Princess. Int Marit Health. 2020; 71(1): 5-8, doi: 10.5603/ MH.2020.0003, indexed in Pubmed: 32212140.

6. Mallapaty S. What the cruise-ship outbreaks reveal about COVID-19. Nature. 2020; 580(7801): 18, doi: 10.1038/d41586-020-00885-w, indexed in Pubmed: 32218546.

7. Rocklöv J, Sjödin H, Wilder-Smith A. COVID-19 outbreak on the Diamond Princess cruise ship: estimating the epidemic potential and effectiveness of public health countermeasures. J Travel Med. 2020; 27(3): taaa030, doi: 10.1093/jtm/taaa030, indexed in Pubmed: 32109273.

8. Mouchtouri VA, Dirksen-Fischer M, Hadjichristodoulou C. Health measures to travellers and cruise ships in response to COVID-19. J Travel Med. 2020; 27(3): taaa043, doi: 10.1093/jtm/taaa043, indexed in Pubmed: 32211801. 